Francisco Walker Linares

\title{
Impresiones de un viaje a la Unión Soviética
}

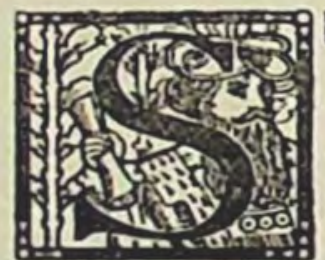

ERIA ABSURDO emitir opiniones dogmáticas acerca de un país tan enorme como la Unión Soviética, la sexta parte del globo terrestre, cuando se ha permanecido solamente una quincena en Moscú y en Leningrado; sin embargo, estimamos conveniente dar a conocer con toda objetividad las impresiones recogidas en la experiencia interesantísima de una visita a la URSS como huésped oficial en un momento histórico trascendental, el de la conmemoración en noviembre de 1957 de los cuarenta años de la revolución de 1917. No puede juzgarse a la Rusia y a sus habitantes con criterio occidental, porque nos encontramos frente a otro mundo, con otra mentalidad, otra concepción de la vida, y cuya organización económica difiere substancialmente de la nuestra. Es preciso tener presente, aún cuando no se esté de acuerdo con ellos, los principios fundamentales del marxismo-leninista, especie de nueva mística, de creencia religiosa materialista, en la cual están formadas y plasmadas las actuales generaciones soviéticas; según esta doctrina de una sociedad sin clases, los bienes que son instrumentos de producción no pueden ser objeto de apropiación individual, están 
socializados, son del dominio del pueblo; la economía no está regulada por la ganancia sino por las necesidades colectivas; la planificación es absoluta para acelerar así la industrialización y la construcción socialista. La propiedad privada subsiste sin restricciones sobre los bienes muebles, y sobre todo lo que es producto del trabajo personal, como ser salarios u otros ingresos, de los cuales se puede disponer libremente.

Dentro de tal organización que exige una disciplina rígida y en la cual el partido comunista, la vanguardia del proletariado, tiene privilegios y poder omnímodos, la libertad individual aparece demasiado disminuida, en forma que choca con nuestra mentalidad democrática occidental, pero al efecto cabe preguntarse si alguna vez en su historia el pueblo ruso gozó de libertad. El aislamiento espiritual es completo; nada se sabe de lo que acontece en occidente, y se ignoran las condiciones de existencia en los países llamados capitalistas; no llegan libros ni publicaciones del extranjero; en el suntuoso hotel en que nos alojábamos en Moscú, únicamente se encontraban los diarios comunistas "L'Humanité" de París, "L’Unita" de Roma y los de Berlín oriental. En las librerías tampoco hay obras en idiomas extranjeros; no obstante se traducen en muchos millares de ejemplares libros de autores consagrados de las letras universales, como Shakespeare, Balzac, Víctor Hugo. A pesar del aislamiento señalado y del pensamiento dirigido, nótase, a través de ciertas preguntas formuladas por los jóvenes, inquietud y curiosidad intelectual; se percibe el deseo de viajar al exterior, de conocer otras tierras más allá del hermético mundo comunista.

La impresión general que tuvimos al llegar a las dos grandes metrópolis rusas fue superior a la que imaginábamos de acuerdo con las informaciones que circulan en occidente; las gentes en las calles se ven modestas pero adecuadamente vestidas dentro de una monótona uniformidad; van abrigadas y su aspecto nada tiene de famélico, sino de bien nutridas. No parecen alegres, pero tampoco tristes ni temerosas; en la juventud que circula no se adivina ese goce de vivir propio de la edad, ni se ven manifestaciones cariñosas de parejas de enamorados; la seriedad del marxismo-leninista mira quizás como 
una debilidad peligrosa las expresiones del amor. Las mujeres por lo general son poco elegantes, carentes de coquetería y de fina silueta; los vestidos femeninos que se muestran en las vidrieras de las tiendas son feos y de calidad ordinaria. La leyenda del encanto cautivador de la mujer rusa se desvanece en Moscú o en Leningrado; tampoco vimos damas elegantemente presentadas en las recepciones o entre la concurrencia de los teatros; sólo nos parecieron bonitas y refinadas algunas bailarinas de los magníficos ballets. En cambio, los niños están cuidados con esmero, se les ve fuertes y contentos; la URSS mira en ellos el porvenir y las reservas de la nación. Los mendigos y los harapientos $ł$ an desaparecido totalmente en ambas ciudades; no existe la prostitución, que era tan frecuente durante el zarismo, a juzgar por los relatos de los novelistas de esa época. Las calles son excepcionalmente limpias, en el Metropolitano impecable de Moscú, no hay un papel en el suelo; en este sentido la disciplina debe ser muy estricta; cuando se regresa de Rusia se encuentra sucio a París, pero de una suciedad muy simpática. Se ha extinguido, pues, otra lacra, proveniente también de los tiempos zaristas, la de la mendicidad y de la suciedad en el pueblo de Moscú o de la ex San Petersburgo.

$\mathrm{El}$ comercio es poco surtido y casi no ofrece tentaciones al viajero occidental; predominan las mercaderías esenciales, escasean las superfluas o suntuarias, por cuanto la planificación económica está dirigida hacia el desarrollo de la industria pesada, y se trata de disminuir el consumo de aquello que no sea indispensable, fijándole precios elevados. Se exceptúan ciertos artículos que no son caros, aunque no sean esenciales, como los aparatos de radio y de televisión, pues ambos son eficaces instrumentos de propaganda; asimismo las máquinas fotográficas, de muy buena calidad, y los discos son mucho más baratos que en cualquier otro país. El costo de la vida parece bastante alto, tal vez el doble que en Francia, de suerte que los salarios no tienen todavía un suficiente poder adquisitivo, a pesar de su alza progresiva y del rápido mejoramiento de las condiciones de existencia. Fuera de los espléndidos teatros y de otros espectáculos públicos excelentes, diríase que en las grandes ciudades rusas faltaran las 
distracciones y que ellas fueran aburridas; las tiendas no seducen; no hay cafés, la vida nocturna es escasa en Moscú; las calles son por lo general sin atractivos y monótonas; las nuevas construcciones, altos edificios de departamentos de alrededor de ocho o diez pisos, todos iguales, se parecen en su uniformidad a los de una ciudad sin alma del Middle West americano; de igual modo ciertos recientes edificios moscovitas suntuosos, que desdicen de la austeridad ambiente, son de un marcado mal gusto. Leningrado en cambio es una bellísima ciudad de armoniosas líneas y lindas perspectivas.

Un gravísimo problema que afecta a la Rusia actual, debido primordialmente al ritmo acelerado de la industrialización, es el de la escasez de habitaciones; se vive en malas condiciones en espacios reducidísimos. En Moscú, la población de la ciudad ha crecido en un millón de habitantes en 1917 a cinco millones en 1957; por consiguiente el déficit de casas es enorme, no obstante los esfuerzos realizados en nuevas construcciones; mucha gente habita todavía en tugurios, que a menudo se encuentran al lado de los magníficos edificios recién construidos. Los dirigentes soviéticos no ocultan la gravedad del problema habitacional.

El pueblo ruso en sus relaciones humanas nos pareció encantador; tuvimos al respecto una gratísima sorpresa; la rigidez dogmática del marxismo-leninista no lo ha deshumanizado; las gentes se muestran suaves, amables, generosas; a pesar de la barrera del idioma, porque casi nadie habla lenguas extranjeras, siempre sentimos junto a nosotros una simpática cordialidad.

La URSS atribuye una importancia trascendental a la educación, a la cual destina enormes sumas en su presupuesto; el analfabetismo, según las declaraciones oficiales, ha desaparecido del vasto territorio soviético; tal vez en ello haya exageración, pero es indudable que está en vías de desaparecer; el esfuerzo ha sido extraordinario si se considera que en la época zarista el $80 \%$ de la población del imperio era. analfabeta. La educación es unilateral, integralmente marxista-leninista, y en consecuencia, atea y materialista; mediante ella el régimen soviético, en cuarenta años de existencia, se ha apoderado de las 
mentes de varias generaciones; los niños le son muy necesarios; es preciso velar por ellos, cuidarlos, mantenerlos contentos y sanos e instruirlos de manera que se impregnen en la doctrina comunista. En la educación especial y superior se atribuye un lugar primordial a la técnica, con preferencia a la humanística; en la URSS existe un fervoroso culto por la máquina, y el objetivo fundamental del gobierno y del partido es la industrialización completa del país a fin de llegar al primer puesto en el mundo sobrepasando a los Estados Unidos; se intenta pues poner en práctica la célebre frase de Lenin, "el comunismo es el poder soviético más la electrificación del país”. Hay un vivo entusiasmo entre la juventud por las carreras técnicas porque en ellas se ganan salarios elevados y se conquistan posiciones privilegiadas. El progreso técnico y científico es sorprendente, y salta a la vista del viajero; maquinarias, automóviles, aviones, aplicaciones atómicas, poderosas y temibles armas de destrucción; durante nuestra permanencia en Moscú, sorpresivamente se lanzó al espacio el segundo Sputnik, el 3 de noviembre de 1957, en vísperas del cuadragésimo aniversario de la revolución, para de esta manera hacer sentir al pueblo el alto grado de perfección a que había llegado la ciencia soviética.

Los festejos de los cuarenta años de la revolución de 1917, constituyeron algo así como el Concilio Ecuménico del comunismo mundial, reuniéndose en Moscú todos los jefes de las repúblicas y democracias populares de tipo comunista, salvo Tito, los altos dirigentes de los partidos comunistas de los diversos países, es decir, las vedettes del comunismo internacional, y huéspedes de toda suerte de nacionalidades, en especial de aquellos pueblos antioccidentales, a los cuales la URSS quiere atraer a su órbita. El mariscal Tito no concurrió porque estaba resentido con la Unión Soviética con motivo de la brusca eliminación del Mariscal Zukoff del gobierno ruso, a raíz de su visita a Yugoeslavia; Tito pretextó un lumbago diplomático. En el enorme y lujoso Hotel Leningrado de Moscú, donde estábamos alojados, éramos cerca de quinientos los invitados oficiales; se nos trataba con cordialísima atención, y contábamos con activos y agrada- 
bles intérpretes. Los huéspedes de nuestro hotel formaban un conjunto cosmopolita, animado, exótico, pintoresco; había allí mongoles, indonesios, birmanos, indúes, negros, árabes, etc.; los países de occidente, incluso los Estados Unidos, estaban también representados; entre los ingleses se destacaba el curioso Deán rojo de Cantorbery, alto dignatario de la Iglesia Anglicana, ya entrado en años, y entusiasta admirador de la URSS. Respecto a los invitados de la América Latina, la selección fue en algunos casos poco acertada; vinieron ciertos individuos de segunda o tercera categoría, que carecían de personalidad, independencia y discernimiento.

Recordaremos siempre como los más inolvidables acontecimientos de la conmemoración revolucionaria moscovita de noviembre, el desfile de la Plaza Roja y la sesión del Soviet Supremo de la URSS. El espectacular desfile se realizó el 7 de aquel mes, el día preciso del cuadragésimo aniversario, en la amplia Plaza Roja de Moscú, al costado del Kremlin; sobre la gran mole de granito que cubre el mausoleo de Lenin, se hallaban Kruschev (los rusos en las traducciones oficiales que hacen al español lo llaman Jruschov), los miembros del Soviet Supremo de la URSS, los jerarcas de las democracias populares y del comunismo mundial; nosotros estábamos con los demás huéspedes a corta distancia en una situación excelente; no había pueblo en el recinto de la Plaza Roja, solamente invitados privilegiados. El desfile, impecable en su organización, nos produjo el efecto de una imponente representación de masas, dividida en tres actos; el primer acto, nos dejó atónitos, era aterrador, se mostraba en toda su orgullosa fuerza el poderío militar soviético; vé́amos grupos de tropas equipadas con el mayor esmero, grandes carros blindados, enormes tanques, cañones de largo alcance ultramodernos, y los extraños y temibles cohetes voladores teledirigidos; con tales armas, fruto de un adelanto técnico y científico formidable, se puede destruir al mundo entero. En seguida, como segundo acto pacifista, después del despliegue bélico, se presentaron innumerables grupos deportivos juveniles, de ambos sexos, como en una especie de inmenso y alegre ballet acrobático circulante de millares de intérpretes, en el que en 
brillante derroche de fantasía alternaban las banderas, las guirnaldas, las alegorías multicolores, los símbolos de paz, las palomas, los sputniks, los retratos de Lenin; diríase un carnaval maravilloso, una farándula feérica; los rusos son maestros en los espectáculos de masas. En tercer término presenciamos la ordenada manifestación del pueblo con delegaciones de los barrios de Moscú y de las diversas regiones de la URSS con sus trajes típicos. Bien valía el viaje a Rusia, aún cuando sólo fuera para asistir a tan impresionante manifestación. En las noches de las fiestas de noviembre hubo iluminaciones especiales en Moscú, con profusión de luces y fuegos artificiales, y en el cielo oscuro se veía brillar fantásticamente un gran retrato luminoso de Lenin. El 7, inmensas muchedumbres paseaban por la calle Gorki, la arteria principal céntrica moscovita, pero no hacían manifestaciones extraordinarias de entusiasmo; el pueblo ruso es un tanto apático; en los mejores teatros aplaude poco, aunque se representen obras exaltando el sentimiento revolucionario; la propaganda política se repite demasiado para que consiga exaltar a los espíritus.

La sesión solemne del Soviet Supremo de la URSS conmemoratoria de los 40 años, se verificó en el estadio cerrado de Moscú, con capacidad para treinta mil personas; en un gran escenario presidían los miembros del Soviet Supremo, los jefes de estado del mundo comunista de $950.000,000$ de habitantes, como Mao-Tse-Tung, el líder de la República Popular China de seiscientos millones de almas; Ubrich, de la Alemania Oriental; Gromulka, de Polonia, el menos dictatorial de los gobernantes comunistas; Kadar, el fatídico represor del levantamiento del pueblo húngaro; Ho-Chih-Minh, de la Indochina; dirigentes comunistas de Occidente, como Palmiro Togliati, de Italia; Maurice Thorez, de Francia; y hasta la Pasionaria, hoy residente en Rusia, por el comunismo español; era impresionante ver de cerca a los más célebres personajes del mundo revolucionario de hoy día. Detrás de estos pontífices máximos del marxismo-leninista, y a manera de altar de la nueva religión, se alzaba un gran busto de Lenin, rodeado de flores, plantas, banderas rojas, estrellas, hoces y martillos. Allí Kruschev leyó durante tres horas un interesante, pero 
uń tanto pesado informe sobre los 40 años de la URSS, cuya interpretación simultánea se podía escuchar en varios idiomas, incluso en español; apoyado en cifras estadísticas (los soviéticos son muy aficionados a las estadísticas), el camarada K. señaló los progresos alcanzados durante ese lapso a través de los planes quinquenales en el orden industrial, técnico, científico, educacional; se refirió con optimismo a las perspectivas para el futuro a fin de convertir a la Rusia en la primera potencia industrial. Reconoció que a pesar de los avances ya realizados, en la agricultura y ganadería el progreso hasta ahora ha sido insuficiente; expresó que algo análogo acontecía en materia de viviendas. Abordó temas candentes y muy delicados, como el del culto a la personalidad; condenó los errores de Stalin, sin desconocer por ello el valor de su obra; amenazó a los que bajo el pretexto del antistalinismo tratan de sabotear el sistema socialista; denunció como traición y desviación la llamada vía nacional del comunismo, aún cuando reconoció que los métodos de edificación socialista pueden variar de un país a otro; tuvo frases amenazantes en política internacional, atacó al Occidente calificándolo de agresivo, insistiendo en los deseos de paz de la URSS. La concurrencia estaba formada principalmente por micmbros del Partido Comunista de toda la Unión, quienes no exteriorizaban un gran entusiasmo ni por los ilustres dirigentes ni por el informe de K.; los aplausos nada tenían de delirantes; nos llamó la atención que entre los componentes del partido, las personas jóvenes eran muy escasas; casi todos parecían mayores de cuarenta años; para llegar a la situación privilegiada de pertenecer al partido es preciso someterse a las largas pruebas de un verdadero noviciado.

Nos interesó particularmente el problema de la religión en la URSS y hemos llegado a la conclusión pesimista de que el cristianismo está en vías de desaparecer en el territorio de la Unión Soviética; desde hace cuarenta años se forman las juventudes en una educación atea y materialista, de modo que el cristianismo ortodoxo se ha ido paulatinamente transformando en una religión de viejos. Nos parece que para los jóvenes soviéticos de hoy día, el cristianismo no 
es considerado con hostilidad, sino como una caduca superstición de sus abuelos, que pudo producir en el pasado un tesoro artístico de bellas iglesias y hermosos íconos; es algo semejante a lo que nosotros sentimos respecto al paganismo helénico. La iglesia ortodoxa rusa, de carácter muy nacional, estaba excesivamente vinculada y sometida al zarismo, sin el sentido universal del catolicismo; el Soviet la combatió duramente como a una fuerza antirrevolucionaria durante los primeros años del régimen; después de haberla debilitado, y cuando cesó de ser un peligro, la toleró, concediéndole una mínima libertad, pero negándole toda actividad social o educadora; el culto se practica en algunas iglesias que se mantienen abiertas. En Moscú y en Leningrado las catedrales e iglesias de mayor valor histórico o artístico están convertidas en museos o en sedes de sindicatos o de otras organizaciones populares; apena ver desafectados y fríos esos santuarios eslavo-bizantinos de elegantes cúpulas doradas con su doble cruz ortodoxa, símbolos de la Santa Rusia, y cuyo interior adornan piadosos íconos, herencia de Bizancio, de la Virgen, de los arcángeles y de los santos.

En Leningrado asistimos a la misa ortodoxa de una de las pocas iglesias de mérito artístico que subsisten abiertas; la liturgia solemne y arcaica, muy oriental, era hermosa e impresionante, de gran ceremonial ritualista con cantos, incienso y cirios, de mayor brillo que el austero rito latino del catolicismo; la música y los coros eran espléndidos; la concurrencia que llenaba el templo estaba formada casi totalmente por personas mayores de sesenta años, sobre todo mujeres, que seguían el oficio con extraordinario fervor; la ausencia de jóvenes y de niños era absoluta. Evocamos asimismo la visita en Moscú a la caída de una tarde otoñal a una vieja iglesia ortodoxa, un tanto derruida, plena de un melancólico encanto místico, envuelta en la penumbra, iluminada únicamente por el débil resplandor de las lámparas y velas del santuario y de los íconos, ante los cuales unas pocas viejas oraban prosternadas; ese templo en las sombras nos pareció el triste símbolo de la ortodoxia rusa agonizante.

En cuanto al catolicismo, cabe observar que en la antigua Rusia 
zarista esta religión fue siempre hostilizada, siendo Polonia y Lituania las únicas regiones católicas del imperio; San Petersburgo y Moscú eran totalmente ortodoxas. En Moscú fuimos a misa el domingo a las ocho de la mañana a la única iglesia católica de la ciudad, que data del siglo XIX, que antes fue francesa y hoy es polaca; el templo estaba bien tenido, completamente lleno de fieles, viejos en su mayoría, principalmente extranjeros, sobre todo polacos; era conmovedor el fervor de la concurrencia, de las mujeres que avanzaban de rodillas hacia el altar; diríase en la semioscuridad que estábamos en la iglesia del silencio o de las catacumbas, pues no se leyó ni se comentó el Evangelio; no sabemos si esto también acontecía en la otra misa que se celebraba más tarde, a las once. Es del caso señalar que en un guía de Moscú, destinado a los turistas, entre las informaciones que se dan acerca de la ciudad, figuran las de los oficios religiosos, entre ellos los de la iglesia católica. En Leningrado la iglesia católica es mejor que la de Moscú; allí asistimos a una misa mayor cantada, bastante solemne, incluso con niños de coro; actuaban dos sacerdotes, uno de ellos leyó el Evangelio y predicó en ruso; en el público, también muy fervoroso, veíamos unos pocos jóvenes y niños, probablemente extranjeros, quizás polacos. Tuvimos la impresión que en Leningrado había mayor libertad religiosa, debido tal vez al carácter báltico de la ciudad, más europea que Moscú.

Pensamos que vale la pena recordar nuestra visita a un Kolkos, es decir, a una hacienda rural cooperativa-colectiva, situada a más o menos treinta kilómetros de Moscú; creíamos, de acuerdo con lo que se dice de Rusia en Occidente, que iríamos a ver una explotación agrícola modelo, ad hoc para mostrarla a huéspedes extranjeros; sin embargo, no aconteció así, por cuanto aquel Kolkos por sus métodos atrasados y poco mecanizados, más que una finca moderna y progresista, parecía una descuidada hacienda chilena de fines del siglo pasado; en la lechería las vacas eran de razas diferentes y flacas y los establos deficientes; de igual modo los cerdos se encontraban en condiciones poco higiénicas. El director del Kolkos, con marcado aspecto de burócrata burgués, muy bien vestido, pero en forma inade- 
cuada para dirigir un predio agrícola, nos dio cifras estadísticas que mostraban una producción poco intensiva y salarios bajos; indicó que antes de 1953 (fecha de la muerte de Stalin), el Kolkos marchaba muy mal, pero que desde entonces, época del comienzo de su administración, todo se había mejorado. Las utilidades del Kolkos se reparten entre los campesinos que lo trabajan, sus productos se venden a los precios oficiales, pagándose al Estado un impuesto poco cuantioso; cada kolkosiano tiene junto a su casa una pequeña extensión de terreno que cultiva para sí y cuyos productos puede vender libremente. El Kolkos, la forma más corriente de la explotación colectiva del campo soviético, es una especie de cooperativa socialista de producción, pero no es una institución integralmente comunista. Suponemos que en otras regiones de la URSS, de mayor fertilidad que la zona moscovita, haya kolkoses más progresistas y mecanizados que aquél que se nos mostró. Después de la visita al Kolkos, los kolkosianos nos ofrecieron un simpático almuerzo en un gran club deportivo a las orillas del Moscova, en los alrededores de Moscú; la reunión fue muy agradable, las mujeres kolkosianas nos atendieron gentilmente y nuestro lenguaje con ellas consistió en señas, reverencias, sonrisas y brindis de vodka, incoloro y peligroso licor que parece fuego; el almuerzo fue pantagruélico, se inició con caviar y tantos fiambres de carnes, pescados y variadas ensaladas, que pensamos que se trataba de una comida fría, pero grande fue nuestra sorpresa cuando después llegaron los platos calientes; el banquete duró cuatro horas; las kolkosianas, e incluso las muchachas que servían a la mesa, bailaron con soltura y agilidad danzas folklóricas; cantó un coro de campesinos, dirigido por el propio director del Kolkos. Uno de los recuerdos más gratos que conservamos de nuestra permanencia en la URSS, es el de aquel almuerzo kolkosiano, en el cual pudimos palpar la espontánea bondad del pueblo ruso.

\section{I}

Fuimos a Rusia invitados por el VOKS (Departamento de Relaciones Culturales de la URSS con el Extranjero), a fin de concu- 
rrir en noviembre de 1957 a los actos conmemorativos de los cuarenta años de la revolución de 1917; la invitación nos fue hecha en Santiago de Chile por intermedio del Instituto Chileno-Soviético de Cultura. El viaje lo realizamos desde Buenos Aires hasta París por Air-France, a bordo de un espléndido y cómodo avión que nos hacía sentirnos desde la iniciación del vuelo, en pleno ambiente francés y parisiense. En la Embajada Soviética en París, ubicada en un severo y aristocrático palacio de la rue Grenelle que antes fuera la sede de los embajadores zaristas, fuimos atendidos con la mayor gentileza, arreglándose nuestra partida a Moscú, vía Praga. El trayecto sin escalas de París a Praga se hizo en un magnífico cuadrimotor AirFrance, a un promedio de quinientos kilómetros por hora; cruzamos por los aires la llamada Cortina de Hierro, entrando en el cerrado mundo comunista. En el aeródromo de Praga tuvimos la sorpresa de encontrarnos con el ultramoderno avión soviético TU 104, de propulsión a chorro, prodigio de la ciencia de la URSS, que en menos de dos horas nos llevaría a Moscú, a una velocidad de más de mil kilómetros por hora, a 11,000 metros de altura y a 50 grados bajo cero; sentimos la impresión de ir viajando dentro de un enorme cohete o en un sputnik en dirección a la luna; el aparato, bastante grande, para ochenta pasajeros, es más largo y más angosto que los aviones ordinarios, carcce de hélices, lo que produce una extraña emoción; porque siempre en nuestra mente la imagen del avión está asociada con la de las hélices, como algo inseparable. En uno de estos aparatos llegó hace algunos meses Gromyko a Nueva York, despertando la admiración y la curiosidad de los norteamericanos; numerosos TU 104 vuelan sobre el territorio soviético y entre la URSS, las democracias populares y la China. Nuestro vuelo, mientras velozmente se atravesaban a gran altitud los cielos de Checoeslovaquia, Polonia, Bielorrusia y parte de Rusia, se hacía en condiciones excelentes, con aire acondicionado y sin el menor malestar por la rapidez o por la altura; las "hostesses" rusas, un poco gordas, tan amables como las francesas o norteamericanas, pero menos estilizadas, atendían gentilmente a los viajeros de múltiples nacionalidades que 
acudían a las fiestas de Moscú, ofrecían caviar, vodka o vinos generosos de Crimea, y creaban una atmósfera de cordialidad; ese vuelo fantástico fue nuestro primer contacto con el mundo soviético. Aterrizamos ya de noche en el aeródromo de Moscú, muy animado y de gala ante la llegada de Ho-Chih-Minh, el líder comunista indochino, y de otros visitantes ilustres. Un grupo de funcionarios del VOKS nos esperaba; a mi mujer la recibieron con un ramo de flores. En un lujoso y enorme automóvil de fabricación rusa, nos llevaron a la ciudad, distante en treinta kilómetros del puerto aéreo, por una autopista de primer orden; se llega a Moscú pasando por nuevos barrios, siguiendo una ancha avenida con recientes edificios de más o menos ocho pisos de departamentos de construcción uniforme; a cierta distancia se divisaba en las sombras la silueta del enorme edificio de la Universidad, con una luminosa estrella roja sobre su altísima torre; después cruzábamos el Moscova, pasábamos junto a los muros del Kremlin, y en la noche su conjunto singular, extraño e imponente de torres, cúpulas y palacios, producía un efecto fascinador; atravesábamos los barrios céntricos, profusamente iluminados a causa de las fiestas. La impresión inicial de Moscú era favorable; en los días que siguieron esta impresión se modificó en parte cuando pudimos ver como en la vecindad de los nuevos edificios subsistían habitaciones muy deficientes.

Nos instalaron en el suntuosísimo Hotel Leningrado, imponente inmueble de más de veinte pisos, construido hace tres años, con una elevada torre y estrella moscovita, imitación de las torres del Kremlin; su lujo era exagerado y de dudoso gusto; diríase una mansión de nuevos ricos por la pesada profusión de mármoles multicolores, los recargados salones en cada piso, la mediocridad de los cuadros que lo ornamentaban; carecía de planificación, pero contaba con todo el confort de un hotel moderno; nos alojaron a mi esposa y a mí en una verdadera suite princiere, un departamento de cinco piezas, dormitorio, baño, salón, escritorio, comedor, piano, refrigerador, televisión, dos radios; nunca hemos disfrutado de un alojamiento más lujoso que el de la capital de la Unión de las Repúblicas Socialistas 
Soviéticas. Eran huéspedes del hotel invitados de las más diversas nacionalidades, muchos de ellos personajes exóticos o pintorescos, lo que creabá un ambiente de vivo colorido y apasionante interés. El servicio era impecable, el personal amabilísimo, como en los mejores palaces de Occidente; recordamos la figura venerable y erguida de un viejo portero de larga barba, que parecía héroe de una novela de Tolstoi y cuyo elegante uniforme le daba el aspecto de un almirante de la Corte del Zar. El Hotel Leningrado fue para nosotros un curioso centro de observación del medio cosmopolita que gira alrededor de la URSS, medio que desconocíamos totalmente; en las horas de comida y cena aumentaba la animación, el público se alegraba, y durante ellas, cosa sorprendente, la orquesta tocaba música bailable de jazz norteamericana. Hay además en Moscú otros hoteles de recargada suntuosidad y estilo kremlinesco; en uno de ellos, el Hotel Ucrania, el VOKS ofreció una lujosa recepción a las delegaciones extranjeras; en la concurrencia, que seguramente estaba bien seleccionada, no se veían mujeres elegantes o bonitas, pero todas vestían con la mayor corrección; la nota discordante la dio un grotesco invitado de un país latinoamericano que llevaba camisa roja porque creía que esa era la tenida adecuada en la patria comunista.

Moscú no es una ciudad hermosa como lo es Leningrado, pero sí muy interesante; su extensión es enorme, quizás mayor que la de París; las distancias son largas; el principal centro moscovita se encuentra en las vecindades del Kremlin, la Plaza Roja y la calle Gorki; hay además otros centros locales en diversos barrios; la orientación se hace difícil a través de sus calles cruzadas por grandes avenidas circulares que forman especies de anillos, y a causa del Moscova, río tortuoso como serpiente, que bordea los muros y torreones del Kremlin ofreciendo perspectivas pintorescas. Es complicado para el turista aventurarse solo por las calles, porque en Rusia es mudo y ciego, debido al desconocimiento del idioma y en especial a la diferencia del alfabeto; en las generaciones actuales casi nadie habla lenguas extranjeras, y a pesar de la amabilidad de la gente, se hace difícil darse a entender. Los invitados teníamos guías, muy cultos y 
agradables, que se ocuparon de nosotros con un programa nutrido que no dejaba tiempo libre; aprovechamos al máximo nuestra corta permanencia.

El tránsito en las calles es mayor que el que imaginábamos, pero inferiōr al de cualquiera gran ciudad occidental; los automóviles que circulan, no muy numerosos, algunos particulares, otros taxis, parecen de buena calidad y son de fabricación rusa. Los transportes colectivos se hacen en cómodos autobuses y trolleybuses, sin aglomeraciones. El ferrocarril metropolitano, el más fastuoso del mundo, es el orgullo de Moscí y una de las más notables curiosidades de la ciudad; tiene cuatro líneas de 65 kilómetros de longitud; cada una de sus numerosas estaciones es un monumento de mármoles multicolores, mosaicos, lámparas enormes, con derroche de un lujo inútil, recargado en exceso; se llega a los trenes, que pasan a mayor profundidad que en otros subterráneos, por escaleras mecánicas; los trenes de largos convoyes de coches, circulan con gran rapidez, al intervalo de menos de dos minutos, son muy confortables y de la más perfecta limpieza. El Metropolitano constituye uno de los exponentes máximos de la arquitectura moscovita de hoy día; admiramos la grandiosidad de su obra, la eficiencia de sus servicios, la riqueza de su ornamentación, pero no podemos considerarlo hermoso.

El Kremlin se impone como la maravilla de Moscú por su belleza original sin igual y por su estilo único; es como una especie de ciudad fortaleza en forma triangular, de 26 hectáreas, rodeada de muros rojos y veinte elegantes torres de diferentes alturas, que terminan en agujas estrelladas; la más hermosa de las torres y la más alta, se yergue en la Plaza Roja junto al mausoleo de Lenin. Su conjunto es imponente a la vez que armónico, a pesar de las construcciones dispares que lo integran, frutos de diferentes épocas, del siglo XV hasta el XIX; encarna toda la agitada historia moscovita, desde los tiempos de Iván el Terrible, de la Santa Rusia zarista y ortodoxa hasta los de la Unión Soviética, a cuyo gobierno sirve de sede. El Kremlin evoca tanto a la larga sưcesión de los zares autócratas, como a Lenin y al comunismo internacional. Dentro de él hay 
tres catedrales, cuyas cúpulas doradas le dan una nota bellísima bizantino-moscovita; estas catedrales son la de la Anunciación, del siglo XV, la del Arcángel, del XVI, que fue durante un tiempo sepulcro de los soberanos, y la de la Asunción, donde se coronaban los zares; las tres se encuentran desafectadas, lo cual produce una impresión penosa, como si hubieran perdido su alma; sus pinturas religiosas inspiradas en Bizancio, pero de un arte auténticamente ruso, son fascinadoras por el colorido, el oro de los viejos íconos y la expresión de un misticismo diverso al de Occidente; recuerdan a veces, sin embargo, la inspiración bizantina de Cimabue o del Giotto. El museo del Kremlin muestra los fantásticos tesoros acumulados por los zares en coronas, cetros, piedras preciosas, joyas, objetos de oro y plata, monturas, como asimismo ricas casullas, hermosos misales. El gran Palacio del Kremlin, elegante construcción de la primera mitad del siglo XIX, de líneas sobrias y blancas, antes residencia imperial, es ahora asiento del gobierno soviético; allí se celebran las sesiones del Soviet Supremo de la URSS y se orientan las actividades del comunismo internacional; aquel palacio nos hizo la impresión de algo como el Vaticano comunista. La perspectiva ofrecida por el conjunto del Kremlin con sus muros, torres, cúpulas y palacios, cuando lo contemplábamos desde las márgenes del Moscova, a la caída de la tarde otoñal, era de una belleza única y de un encanto inolvidable.

La Plaza Roja, llamada así desde hace siglos como sinónimo de Plaza Bella, está junto a las murallas del Kremlin y al pie de sus torres; tiene más de trescientos metros de longitud; allí se alza el majestuoso mausoleo de Lenin en mármol negro y pórfido granate, el cual guarda la tumba del fundador del Estado soviético, y también la de Stalin; los cuerpos de ambos están perfectamente conservados; es impresionante contemplar en la penumbra del sarcófago el rostro amarillento de Lenin, fallecido en 1924, y que parece estar durmiendo. Colas enormes de personas esperan a toda hora su turno para desfilar ante el sepulcro de Lenin y rendirle homenaje; su tumba es como el Sancta Sanctorum de la nueva mística. El culto de Lenin ha llegado a la apoteosis en los festejos de los cuarenta años de la revolución; 
innumerables retratos suyos, de todos los tamaños, cubrían, y a menudo afeaban, las calles de Moscú en los primeros días de noviembre. En la Plaza Roja se destaca, admirablemente ubicada, la curiosa Catedral de San Basilio, la más original de las iglesias rusas, rarísimo edificio, multicolor y retorcido, pero artísticamente armónico, con una gran torre y cuatro cúpulas, mandado construir en el siglo X:̣I por Iván el Terrible. La Catedral de San Basilio es otra de las imágenes representativas que evocamos con nostalgia al recordar Moscú. Vecino a la Plaza Roja se halla el GUM (los Grandes Almacenes Universales), enorme tienda que ocupa cuatro mil empleados, siempre repleta de público, que vende toda clase de artículos, por lo general poco tentadores para quienes vienen de Occidente, salvo las máquinas fotográficas que son buenas y baratas y los discos. Hay asimismo una gran tienda destinada especialmente para los niños. De la Plaza Roja arranca la ancha calle Gorki, la más animada de la ciudad, con altos edificios nuevos, todos más o menos uniformes; en ella se encuentra el Soviet de Moscú, cuyo inmueble que data de fines del siglo XVIII fue desplazado intacto once metros hacia atrás para ensanchar la calle, realizándose un verdadero prodigio de técnica.

Hay en Moscú buenos museos, pero ninguno como el Ermitage de Leningrado; en el Museo Pushkin admiramos un maravilloso conjunto de cuadros de los impresionistas franceses. La Galería Nacional Tretiakov está destinada al arte ruso y contiene una colección de íconos de un primitivismo encantador, de los siglos XV y XVI, época del esplendor del arte religioso moscovita; con posterioridad la pintura rusa no sobresale, siendo inferior a la de los países occidentales; sin embargo, en el siglo XVIII y principios del XIX, hubo notables retratistas. En cuanto al arte pictórico posterior a la revolución de 1917, demasiado dirigido, nos pareció casi siempre mediocre y carente de interés. En el museo de la ciudad de Moscú puede observarse la transformación operada recientemente en esta metrópoli, la cual antes de 1917 era como una inmensa aldea, cuyas clases populares vivían en condiciones deplorables; el progreso urbanístico es manifiesto pero aún queda muchísimo que hacer, particularmente en 
viviendas. Hay asimismo un Museo de la Revolución, y a treinta kilómetros de Moscú, en una aldea llamada Gorki, se encuentra, convertida en museo, casi en un santuario, la casa en la cual Lenin pasó largas temporadas, preparando sus trabajos y discursos, y en la que falleció en 1924; es un lugar bellísimo y apacible, debido a su privilegiada ubicación en una pequeña colina al lado de un bosque; esa casa de elegantes líneas, cómoda, pero sin lujo, pertenecía antes de la revolución al gobernador de Moscú; se veneran como reliquias todos los objetos de uso personal de Lenin, aun los más insignificantes; se conservan y se muestran a los visitantes sus muebles, sus vestidos, los originales de sus escritos. El culto de Lenin crece de día en día, y el cuadragésimo aniversario de la revolución dirigida por él, ha contribuido a su máxima exaltación.

La actividad teatral de Moscú es muy intensa; los moscovitas, cuya vida no es pródiga en distracciones, llenan las numerosas salas de espectáculos, a pesar de los precios elevados de las localidades, divididas en palcos, plateas, balcones, galerías, con tarifas diferentes, como en los países occidentales. No podemos opinar acerca del arte dramático actual ruso, debido a nuestra ignorancia del idioma; entendemos que se presentan obras de una manera perfecta, interpretadas por artistas de primer orden; cabe recordar al efecto la influencia que en la renovación del arte escénico mundial contemporáneo ha tenido el Teatro de Arte de Moscú, fundado en 1898 por el célebre Stanislavski. Hay teatros especiales para niños y buenos espectáculos de títeres. En el Gran Teatro, hermosa y acogedora sala que data de la época zarista, construida en 1856, esmeradamente mantenida, concurrimos al famoso ballet Bolshoi, universalmente conocido, de técnica y orientaciones clásicas tradicionales, no modificadas por la revolución, ajenas al vanguardismo innovador, de escenografía fastuosa e impecable, de vivo colorido, derroche de fantasía y refinado gusto. Asistimos a un lindo ballet, "La Fuente de Baschisarai", con música de B. V. Asafiev, cuya trama muy rusa se desarrolla en los tiempos de las invasiones tártaras; los numerosos intérpretes lucieron en la más disciplinada armonía sus condiciones coreográficas, su prodigiosa 
agilidad, casi acrobática. Los ballets que vimos, tanto en Moscú como en Leningrado, nos hicieron pasar momentos del más puro deleite espiritual, evadiéndonos hacia un mundo feérico. En materia de ópera oímos "Fidelio" de Beethoven, bastante bien cantado y con cuidadosa presentación, y "La Madre", ópera tomada de la novela del mismo nombre de Máximo Gorki, montada de una manera muy realista, sin modernidad; esta obra, estrenada especialmente para los festejos de la revolución, desmerecía en su marcado afán de propaganda antiburguesa, pareciendo más que un drama lírico, la teatralización musical de la novela; las óperas disponen de magnífica escenografía, buenos coros, excelentes orquestas, cuyos músicos visten todos de etiqueta. Noche a noche fuimos invitados a espectáculos diferentes; nos llevaron a un circo de primera calidad y programa muy atrayente, con notables acróbatas, payasos, domadores de fieras, que venían de las distintas regiones de la URSS, de China y de las democracias populares. Estuvimos en un teatro de variedades con muy buenos números musicales, simpáticos bailes del rico folklore de la Unión Soviética, y un prestidigitador estupendo; sin embargo, lo que más aplaudió el público no fue lo mejor de la velada, sino una orquesta de jazz, de la cual el director es un verdadero ídolo popular. Se descubren cosas inesperadas en Rusia. Algo que nos llamó la atención en los teatros soviéticos, fueron los aplausos de los propios artistas intérpretes, respondiendo a los aplausos, la mayoría de las veces fríos, de los concurrentes; diríase que los artistas se aplaudieran a sí mismos.

La nueva Universidad de Moscú, inaugurada en 1956, es sin duda alguna el mejor y el más grandioso edificio moderno de la ciudad, construido con gusto y elegancia; ubicado en una posición de bellas perspectivas en las vecindades del Moscova, domina una pequeña colina, llamada Montaña de Lenin, y se halla rodeado de verdura y de jardines. Es enorme, tiene 32 pisos, más de treinta mil piezas, 37 pabellones; su atrevida torre principal, de estilo moscovita, feliz imitación de las torres del Kremlin, pero mucho más alta, termina en aguja y alcanza a 240 metros. Moscú se enorgullece a justo 
título de su Universidad; frecuentan sus aulas 19,000 estudiantes, entre los cuales son numerosos los extranjeros; cerca de seis mil de estos alumnos viven con becas en el propio inmueble universitario, en cómodos cuartos individuales; por cada dos de estos cuartos hay un baño privado; los estudiantes nos mostraban sus habitaciones con simpática cordialidad. Sus facultades son doce, científicas y técnicas, pues las humanísticas han quedado en la vieja Universidad del centro de la ciudad, la cual carece de pensionado para estudiantes dentro de su edificio. La enseñanza superior soviética está encaminada preferentemente hacia la ciencia y la técnica, indispensables para la obra de industrialización del país. Son numerosos y bien equipados los laboratorios y centros de investigación de la nueva Universidad, que además cuenta con varios museos; nos interesó el museo geológico que muestra las incalculables y variadas riquezas y reservas minerales de la URSS.

\section{I I}

Desde Moscú fuimos a Leningrado por tren nocturno en buenos coches dormitorios; en diez horas se recorren los ochocientos kilómetros de distancia entre ambas ciudades; se atraviesan regiones que parecen poco fértiles, de explotación agrícola rudimentaria; el paisaje es de llanuras monótonas con algunos bosques. Las periferias de Moscú y de Leningrado son de una intensa actividad industrial, con innumerables fábricas, cuyas altas chimeneas surgen de todos lados; las dos ciudades son centros fabriles importantísimos. Leningrado, ex San Petersburgo, ex Petrogrado, la capital que fundara Pedro el Grande hace poco más de 250 años para europeizar a Rusia, es mucho más bella que Moscú, la vieja metrópoli, genuinamente rusa y algo asiática, con ocho siglos de existencia. Su ubicación es privilegiada, extendiéndose a ambas márgenes del ancho y hermoso río Neva, no lejos del golfo de Finlandia, cruzada de canales, con islitas pintorescas, siendo una especie de Venecia nórdica. Es una ciudad muy báltica, plena de encanto, que nos conquista desde el primer 
momento. Las elegantes y atrevidas torres que terminan en largas agujas de su Almirantazgo y de la histórica fortaleza Pedro y Pablo, difieren de las del tipo Kremlin moscovita, le dan una fisonomía original, y evocan a Estocolmo y a Escandinavia. Sus lindos palacios barrocos del siglo XVIII se asemejan a los de la Europa Central; sus grandiosas catedrales de Kazán y de San Isaac, en estilo clásico, un tanto pesado, poco acogedoras, pero admirablemente situadas, no recuerdan a Bizancio como las de Moscú, sino a la Italia renacentista; las dos están desafectadas, y una de ellas, en los primeros tiempos de la revolución de fobia antiortodoxa, fue transformada en museo antirreligioso; después el museo se llamó de historia de las religiones, y en noviembre último estaba cerrado con el pretexto de reparaciones; tales cambios de actitud son el reflejo de las modificaciones de la posición soviética frente a la religión. Hay, además, hermosas iglesias ortodoxas, pocas de ellas abiertas al culto, de estilo ruso-bizantino; no faltan pues en Leningrado las características cúpulas doradas con su dobles cruces de la ortodoxia. En páginas anteriores ya nos hemos referido a su única iglesia católica.

Las calles son anchas, con edificios armónicos y sobrios, muy bien mantenidos, anteriores a la revolución. La avenida principal, que cruza la ciudad en dirección al Neva, la famosa Perspectiva Newsky, es animada y atrayente; agrada e interesa pasear por sus amplias aceras observando al público que allí transita, el cual nos pareció más alegre y comunicativo, y de más alto nivel de vida que el de Moscú. Nos alojamos en el Hotel del Báltico, ubicado en la Perspectiva, simpático, algo arcaico, de la época zarista, pero con comodidades modernas; difería substancialmente de nuestro suntuoso hotel moscovita.

El inmenso Palacio de Invierno, bello ejemplar del estilo barroco, la fastuosa residencia de los zares, privilegiadamente situado en las riberas del Neva, contiene uno de los museos más completos y ricos del mundo, el del Ermitage; hay en él obras maestras de las principales escuelas pictóricas de todas las épocas, incluso Vírgenes de Leonardo de Vinci y de Rafael, y una magnífica colección de impresionistas franceses. Se necesitan muchos días para visitar sus innume- 
rables salas que poseen tesoros, no sólo de artes plásticas, sino también de antigüedades, objetos de valor histórico y cultural, y arte decorativo. La organización del museo es perfecta y los salones del palacio deslumbran por su magnificencia. Lo frecuenta un numeroso público y llaman la atención los grupos de niños escolares, que acompañados de sus maestros, recorren sus diferentes secciones. El Palacio de Invierno ha desempeñado un papel preponderante en la historia revolucionaria rusa; en la imponente y severa plaza que lo enfrenta, uno de los sitios más caracterizados de Leningrado, fue reprimida violentamente por las fuerzas imperiales la muchedumbre desarmada y hambrienta que en 1905 formulaba pacíficamente peticiones al Zar; aquel movimiento de 1905 , en el cual el pueblo perdió la fe en el Padrecito, pues así llamaba al Zar, significa la condenación a muerte del zarismo y el preludio de la futura revolución. La toma del poder por los bolcheviques dirigidos por Lenin, el 7 de noviembre de 1917 (25 de octubre según el antiguo calendario ruso), se realizó también en este mismo lugar, por cuanto era en el Palacio de Invierno donde sesionaba el gobierno provisional de Kerensky, que entonces se derrocó. Los bolcheviques se apoderaban del Palacio, en tanto que desde el Neva lo bombardeaban los marineros rebeldes del crucero "Aurora", barco que hoy se conserva como reliquia revolucionaria. El Palacio de Invierno y su plaza encarnan mucho más que el Kremlin y la Plaza Roja de Moscú, la victoria de la Revolución Soviética, porque fue allí donde se instauró hace cuarenta años el sistema político-social que derrumbó la antigua Rusia autocrática.

A pesar del terrible sitio de tres años sufrido por Leningrado durante la última guerra, al cual resistió heroicamente, la parte céntrica de la ciudad pudo salvarse de los bombardeos y conservarse intacta; aquel sitio horroroso y la magnífica resistencia de los habitantes, ha inspirado la vigorosa y audaz sinfonía "Leningrado" del músico ruso Shostakovich; hemos oído emocionantes relatos de esos aciagos días de crudos inviernos sin fuego y sin abrigo, y en los que faltaban los alimentos más indispensables. En Leningrado no hay en los barrios céntricos nuevas construcciones grandiosas de dudoso gus- 
to que desentonen con la armonía del conjunto, como acontece a menudo en Moscú. Los antiguos palacios de la aristocracia fueron conservados por la revolución, y son ahora museos, o sedes de servicios públicos, educacionales o sociales. Uno de ellos, de amplia extensión, muy elegante y de exquisito gusto, que fue propiedad de la familia imperial, es ahora el Palacio de los Niños Pioneros; varios millares de chicos de las escuelas, alegres, limpios, sanos y bien cuidados, concurren a él por turnos cada día, después de sus clases, mientras sus padres trabajan; allí juegan, se cultivan, se educan físicamente, o se orientan hacia una futura profesión o técnica. El régimen soviético está realizando valiosas experiencias en materia de formación infantil; la del Palacio de los Niños Pioneros nos pareció interesantísima.

Leningrado no ha perdido en modo alguno sus características de gran metrópoli, sigue siendo un centro de intensa cultura; su Academia de Ciencias goza de alto prestigio; su actividad industrial está a la altura de la de Moscú; hay mayores contactos con el exterior, pues la frontera finlandesa se encuentra a corta distancia; sus habitantes parecen más finos, más europeos, menos asiáticos que los moscovitas; todo ello se evidencia en la fisonomía misma de la ciudad, en su clima espiritual. Leningrado tiene también un ferrocarril metropolitano, pero éste es menos suntuoso que el de Moscú.

Leningrado ofrece buenos espectáculos; su vida musical es muy activa, su Orquesta Sinfónica es famosa y ha alcanzado ruidosos éxitos en sus jiras por el extranjero. Su Gran Teatro, el antiguo Teatro Imperial, es el más hermoso que hemos visto en la URSS; allí asistimos al ballet "Flores de Piedra", bellísima fantasía feérica, con música de Prokofiev, basada en un cuento popular; esta misma leyenda inspiró también a una linda película soviética que se dio hace algunos años en Chile; la escenografía y el conjunto coreográfico eran perfectos y de refinado gusto, tan excelentes como los del ballet Bolshoi del Gran Teatro de Moscú. Concurrimos además a "El Corsario", ballet un tanto académico, del músico francés Adam; la presentación fue igualmente impecable. 
De Leningrado queda un recuerdo indeleble; esta ciudad, una de las más hermosas que conocemos, posee singular encanto y magia cautivadora, y sabe acoger con un atractivo único. En los días grises otoñales su belleza nórdica adquiere suaves tonalidades maravillosas; las vagancias por sus calles y plazas y por las orillas del Neva $y$ junto a sus canales, nos descubren a cada instante rincones pintorescos o panoramas fascinadores. Con muchísima pena nos alejamos de ella, y la evocaremos siempre con la más honda nostalgia, soñando en verla nuevamente.

Después de quince días de permanencia en la URSS, salimos de Moscú que ya se tornaba invernal, cubriéndose de una ligera capa de nieve; nos embarcamos en un avión soviético TU 104, del mismo tipo del que nos trajo a Rusia; nos fuimos a Praga, deteniéndonos un día en esa bella ciudad, animada y pintoresca, gótica y barroca, de valiosos tesoros artísticos; cuando se viene de Moscú, en Praga y en sus habitantes ya sentimos el Occidente, a pesar del régimen político checoeslovaco. Al día siguiente un avión de Air-France nos llevó a París.

El viaje a la Unión Soviética, muy diferente a cualquiera otra jira turística o cultural, nos ha dejado una profunda huella, casi una obsesión; a cada instante evocamos ese mundo tan distinto al nuestro; diríase que tuviéramos la misteriosa Rusia en el alma. No aceptamos las doctrina marxista-leninista, ni su materialismo, ni su concepción de la vida; sin embargo, creemos que las relaciones humanas pueden ser amistosas y cordiales con el pueblo ruso, en el cual hemos descubierto condiciones de bondad, generosidad y simpatía, que antes ignorábamos. Tal vez ésta haya sido la mejor experiencia recogida en nuestro apasionante viaje. Ojalá pudiera establecerse un mayor contacto personal entre los occidentales y los rusos; con el mutuo conocimiento de hombre a hombre, al margen de las divergencias políticas, se desvanecerían muchas suspicacias y desconfianzas, y se realizaría una auténtica misión pacifista y humanitaria. 